OPEN ACCESS

International Journal of Management \& Entrepreneurship Research

P-ISSN: 2664-3588, E-ISSN:2664-3596

Volume 2, Issue 4, P.No. 244-261, August, 2020

Fair East Publishers

Journal Homepage: www.fepbl.com/index.php/ijmer

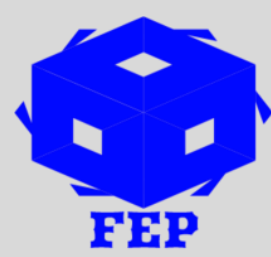

\title{
RELIGIOSITY AND CONSUMER BEHAVIOR: A STUDY OF CONSUMPTION PATTERNS FOR ALCOHOLIC AND NON- ALCOHOLIC BEVERAGES AMONG ANIMIST, CHRISTIAN AND MUSLIM CONSUMERS IN THE CONTEXT OF GHANA
}

\author{
Dr. Théophile Bindeouè Nassè̀ ${ }^{1,2,3}$, Naab Francis Xavier ${ }^{1}$, Bismark Boateng ${ }^{1}$, Nicolas Carbonell ${ }^{4}$, \\ Justice Agyei Ampofo ${ }^{1}$, Adams Sabogu ${ }^{1}$, Eric Dalinpuo ${ }^{1}$. \\ ${ }^{1}$ University for Development Studies, Wa (Ghana). \\ ${ }^{2}$ Thomas Sankara University, Ouagadougou (Burkina Faso) \\ ${ }^{3}$ Saint Thomas D'Aquin University, Ouagadougou (Burkina Faso) \\ ${ }^{4}$ Polytechnick University of Catalonia, Barcelona (Spain).
}

\begin{abstract}
*Corresponding Author: Dr. Théophile Bindeouè Nassè
Corresponding Author Email: nassetheophile2009@gmail.com
\end{abstract}

Article Received: 21-07-20 Accepted: 19-08-20

Published: 05-09-20

Licensing Details: Author retains the right of this article. The article is distributed under the terms of the Creative Commons Attribution-Non Commercial 4.0 License

(http://www.creativecommons.org/licences/by-nc/4.0/) which permits non-commercial use, reproduction and distribution of the work without further permission provided the original work is attributed as specified on the Journal open access page.

\section{ABSTRACT}

Researchers' interest in consumer religiosity and behavior is explained by the fact that religion influences not only the social behavior of individuals, but also their consumption behavior. Most of the studies on the subject come from Western and Asian countries with a few of such studies been conducted in Africa and particularly in Ghana. The aim of this paper is to explore the concepts of religiosity and consumer behavior in Ghana, in order to consider the role of culture in the management and marketing of industrial products. Ghana is a country where religion plays an important role in shaping lives and ensuring community cohesion. However, a determined part of the believers contributes to increasing the consumption of industrial beverages, and the obliviousness in the marketing sector also seems to be a barrier that slows the production and consumption of non-alcoholic industrial beverages. The research approach is exploratory and qualitative. The collection of qualitative data is done with the aid of a SONY voice recorder through some semi-structured interviews. Then, the qualitative data are transcribed manually and verbatim analyzed. The results show that in the context of Ghana, religiosity of believers affects the behavior of the consumer and that consumer behavior towards non-alcoholic industrial beverages affects religiosity. 
Keywords: Religiosity, Consumer Behavior, Industrial Beverages, Consumption, Marketing, Ghana.

\section{INTRODUCTION}

Marketing practices in the context of Africa are new with most marketing research topics often aiming at other sectors because research on religious beliefs and consumption seems taboo (Nasse, Ouédraogo \& Diop, 2016). Conducting research on the present topic in the particular context of Ghana is understandable because similar topics have been developed in America, Asia, Europe, and in some African countries. Therefore, the present research purpose is to establish a comparison with previous results and to test marketing theories. It also provides managerial solutions for businesses to adapt industrial beverages to consumer needs, and expectations and to present some significant managerial contributions for targeting and positioning strategies in understanding customer behavior (Agarwala, Mishra \& Singh, 2018). Therefore, this research is an exploratory study whose subject is focused on the consumption patterns for alcoholic and non-alcoholic beverages among Animist, Christian and Muslim consumers in the context of Ghana. In Ghana, industrial drinks are part of the events of everyday life and customs, and there are more and more consumed. Industrial beverages in the West African context are used for nutrition purposes (Nasse, 2018), religious purposes (Dumbili, 2013; Nasse, 2018) and a medical purpose (Nasse et al., 2016). For example, industrial beverages can be found at events such as funeral rites, traditional wedding ceremonies, wedding ceremonies, religious rituals and ceremonies, religious baptisms, educational and academic ceremonies, on Christmas, on Easter Day, on Scottish holy day, during the Ramadan Feast, during the Tabaski Feast, during the administrative ceremonies, during the celebrations of international events by government authorities during ethnic festivals, and many other gatherings that bring individuals together. For this reason, Porter (2013) points out that purchases of products such as industrial drinks prevail during religious holidays especially during Christmas. In Ghana, religion remains a significant element of people's daily life (Howell, 1996; Nasse, 2012). Thus, religion shapes people attitude, beliefs and their consumption behavior (also see Addo et al. 2018).In addition, industrial drinks and in particular industrial non-alcoholic drinks are food supplements (Sow, 2005; Nasse, 2018) very important for the population, as they help to curb vitamin deficiencies, fight against mineral deficiencies, fight hunger and to relieve thirst. Today, according to national statistics, Ghana is composed of $71.2 \%$ of Christians (28.3\% of Pentecostals or Charismatics, $13.1 \%$ of Catholics and $18.4 \%$ of Protestants and $11.4 \%$ ), $17.6 \%$ of Muslims; $5.2 \%$ of animists, $0.8 \%$ of other religions and $5.2 \%$ without religion [Ghana Statistical Service (GSS), 2010].In animism (Traditional belief system), there are no different denominations, whereas among the Christians there are for example the Adventists, the Assemblies of God, the Apostolics, the Baptists, the Mennonites, the Pentecostals, the Presbyterians, the witnesses of Jehovah, Roman Catholics. Among the Muslims, there are for example the Ahmadiyya, the Shiites, and the Sunnis. In Ghana, an observation is that religious beliefs contribute strongly to encourage the consumption of industrial soft drinks. Religious beliefs thus seem to be catalysts that facilitate the trade and consumption of non-alcoholic industrial beverages. However, little information on this fact leads the sector companies of industrial beverages not to be able to adapt industrial soft drinks 
production to expectations and needs of real consumers. Given that religiosity is one of the major contributors to the consumption of non-alcoholic industrial drinks, the following question arises: What is the perception of religious consumers about the consumption of non-alcoholic beverages as compared to the consumption of industrial alcoholic beverages and why are some believers increasingly oriented towards the industrial consumption of alcoholic beverages rather than the industrial consumption of soft drinks in the context of Ghana?

This research question is structured around the following specific questions:

1) How can we explore religiosity and industrial beverage consumption in the context of Ghana?

2) What is the relationship between the degree of religious beliefs and consumer behavior towards non-alcoholic industrial beverages in religious groups in Ghana?

3) How can religiosity and consumption affect positively or negatively the development of Ghana?

The overall objective of this research is to show the influence of religiosity on consumer behavior in the context of Ghana and how this nexus affects the development of Ghana . The specific objectives of this research are:

1) To explore the relationships between religiosity and consumer behavior in the sociocultural context of Ghana.

2) To examine between the consumer behavior and their religious beliefs vis-à-vis nonalcoholic industrial beverages within religious groups in the context of Ghana.

\section{Justification/Significance of the study}

The enunciation of this theme can highlight the main interest and the theoretical and managerial interests of research. The main interest lies in the theoretical proposition of a conceptualization of religiosity and the behavior of the consumer. Another theoretical interest is the combination of religiosity and consumer behavior concepts and, the links between them. The predominant managerial interest of this research results in a better understanding of the definition of the concepts of religion and consumer behavior, their links as well as the determinants of religion in a particular sector, that of the consumption of soft drinks and alcoholic ones. No study dealing with this topic has ever been implemented in the context of Ghana. On this basis, this exploratory research is a dynamic with high added value in terms of management of companies and industries that are in the industrial beverage sector. It is therefore essential to conduct a study on consumer behavior not only to better meet consumer expectations and because the subject is of great interest, as it also guides economic development policy in the industrial beverage sector. This research is intended to help build peace between consumers of different religious groups where all consumer expectations are taken into account in the production decisions of organizations.

This study begins with a review of the literature on the concept of religiosity and the concept of consumer behavior. In addition, the link between religiosity and consumer behavior is emphasized, then the different theories which anchor the study are highlighted. The final sections look at the hypotheses, the research model, the methodology, the expected results, the contributions to knowledge and the study conclusion. 


\section{REVIEW OF THE LITERATURE}

\section{Definition of key Theoretical and Conceptual issues}

A review of the preceding literature in this research is necessary in order to bring out the different theories and different concepts that come under research.

The Theory of Sustainable Development: Some authors such as Van Den Bergh and Nijk amp (1991), Bidan (2010), Nasse, Ouedraogo and Diop (2019) have pointed out that, consumer behavior should not encroach on the well-being of future generations. There is therefore a need to have a consistent and ethical consumer behavior/patterns given that, it helps in part to protect the environment and preserve it for future generations as well.

The Culturalist Theory: Baazeem (2015), Esteban (2015), Campanella (2016), Nasse et al. (2019) support the culturalist approach of consumer behavior. The culturalist perspective of consumer behavior indicates that the behavior of a given consumer is determined by his or her own culture and that, therefore, some dimensions of cultural consumption are mentioned by these authors.

The Economic Theory: The final theory of interest for this study is the economic theory of consumer behaviour. Under this theory, Simon (2000), Matthew and Morrison (2003), Ouedraogo (2007), Kitchathorn (2009), Nasse (2012), Shamba and Livian (2014) Van Laethem and Body (2008), Nasse (2015) briefly express their ideas in the direction of the economic theory of consumer behavior. The economic theory of consumer behavior indicates that a given consumer will buy back certain products when these products have the greatest value in terms of quality or when these products give absolute satisfaction at a reasonable price in relation to their qualities. Within the context of this study, what this could mean is that, the consumption behavior of religious people at any point in time could depend on the extent to which qualities of the product are not at variance with their belief and value system.

Religiosity: For Bonewell (2008) religiosity is characterized not only by an extrinsic dimension where religion is used for to improve one's personal interest, but also by an intrinsic dimension where religion is integrated is integrated in one's life with a positive attitude. Patel (2010), religiosity is approached as the degree of faith of a believer to a particular religious group. Nasse (2020) defines religiosity as the level of religious beliefs of the consumer, from the perspectives of three religious groups in the context of Burkina Faso, namely the Christians, the Muslims and the Traditionalists with their consumption similarities and their consumption differences. In this research Nasse shows that religiosity has a syncretic dimension of consumption that is more tolerant, and moderated as compared to the non-syncretic dimension of consumption that is less tolerant and fanatic. For Islam and Chandrasekaran (2020), religiosity is rather understood to be the affiliation to a particular religious group with the devotion of showing a religious committment to that group.

Consumer behavior: This concept is defined by several authors who have different points of view according to the socio-cultural context in which they are. In the Western and Asian contexts, the concept of consumer behavior in marketing is defined by several authors. In the American context, authors such as Zikmund and D'Amico (1996) define consumer behavior as being the activities in which people engage by making selections, buying and using products to satisfy their needs and their desires. Ishak et al. (2019) define religiosity as a degree of religious concern about decisions made on the consumption of a given product. For Islam and Chandrasekaran (2020), consumer behavior is understood as the way the consumer makes some 
choices and decision on whether to consume or not to consume some given products. In addition, Sadiq, Ansari and Gupta (2020) demonstrate that religiosity has an intrapersonal dimension and an interpersonal dimension. Intrapersonal religiosity is related to the individual own views about the religious beliefs of a given religion and interpersonal religiosity deals with the religious beliefs as viewed by the whole religious community. Finally, Nasse (2020) views consumer behavior as a syncretic attitude and a non-syncretic attitude of making some consumption decisions. For Nasse, consumer behavior can be defined as the way in which individuals or consumers decide, examine, evaluate, products and services then make choices in terms of purchases, consumption, tastes, compared to their expectations or their satisfaction and personal experience with the use of these products or services.

Religiosity and Consumer Behavior: An individual's religiosity level plays a fundamental role in influencing his or her attitudes, values, and consumption decisions (Agarwala, Mishra \& Singh, 2018). Mathras et al (2016) delineate religion as a multidimensional construct and propose that religion affects consumer psychology and behavior through four dimensionsbeliefs, rituals, values, and community. For instance, authors such as Amankwaa et al. (2012) show with a positivist epistemological stance and a quantitative approach that religiosity and consumer behavior are linked through a study conducted at a University of Georgia in the United States of America. Students who do not consume alcohol or whose alcohol consumption is very low had a strong involvement in religious practice. Their study then revealed that religiosity is closely related to the behavior of consumers towards industrial drinks. Benabdallah and Jolibert (2013) based on a constructivist epistemological position and a qualitative study show that the relationship between religiosity and the consumption behavior of Algerian immigrants in France is significant. According to these authors, if the degree of religiosity of the individual is high, the individual will tend to remain faithful to the consumption practices authorized by his religion (see also Agarwala, Mishra \& Singh, 2018). Campanella (2016), through a post-epistemic epistemological stance and both a mixed approach, demonstrates how religiosity influences the consumer choice of Muslim consumers in Sweden. Campanella notes that $88.7 \%$ of Muslims living in Sweden frequently consume "1halal products" and for those who need answers a religious principle that is the commitment to do what is right. Through a positivist epistemological position and a quantitative approach, Alam et al. (2011) examines the relationship between religiosity and behavior of Muslim consumers in Malaysia and they find that religiosity is a factor that determines the behavior of Muslim consumers. Finally, Al-Hyari (2011) through a constructivist epistemological position and a qualitative approach and a study of consumer behavior in Saudi Arabia, shows that the connection between religiosity and consumption behavior of Saudi Muslims is total, and it is this which explains that these consumers are boycotting a number of products unfit for consumption. Diop (2012) through exploratory research and a qualitative approach shows that there is indeed a relationship between the religious values of Islam and the marketing values practiced in Senegal. Diop demonstrates how belief in the values of the Islamic religion has a particular influence on the behavior of Senegalese consumers. Diop briefly emphasizes that in the particular context of Senegal, beliefs in religious practices influence the behavior of Muslim consumers. In the particular context of Burkina Faso, Nasse, Ouédraogo and Diop (2016) have shown that there

\footnotetext{
${ }^{1}$ A Halal certified product means that the product is permissible or acceptable in accordance with Islamic law. In order for products to receive this certification, they must be from an acceptable source such as a cow or chicken and slaughtered according to these laws
} 
is a clear link between religiosity and the results of consumer behavior through exploratory research and a qualitative and quantitative approach. This explains why some believers, regardless of their degree of belief, contribute to increasing the number of consumers of industrial alcoholic beverages. In Ghana, Christianity is the dominant religion in terms of statistics. A first observation is that Christianity, Islam and the animist coexist in harmony. Another observation is that the practice of religious faith such as Christianity and Islam in Ghana is a moderate practice because of the influence of traditional beliefs (animism) that do not prohibit the consumption of industrial alcoholic beverages. According to Bazié (2011), alcoholic beverages are used in traditional animist rituals in Africa. In addition, in the Ghanaian context within the same family, one can find animists, Christians and Muslims who live together and share the same diets and the same drinks. Therefore, some religious practitioners who are converted from the traditional African religion, and who live in harmony with other religious believers do not rigorously apply the precepts of Islam or Christianity as it should. This contact between foreign religions (Christianity and Islam) and traditional African religion (animism) is called syncretism by Quéchon (1971, p. 206). This religious syncretism known in West Africa can partly explain the fact that some believers, whatever their degree of belief, consume alcoholic industrial drinks (Nasse \& al., 2019) in the context of Ghana. The review of the literature confirms that there is little research on religiosity and consumption of industrial beverages in the West African context (Diop, 2004) and also in the context of Ghana. A further review of the literature shows that, it is good to consider in market research, the concept of culture in market analysis to better understand consumers and their different behaviors. Understanding the differences and similarities in consumer culture can also help companies standardize or direct their marketing strategies to meet the expectations and needs of consumers. The review of the literature also identifies some variables that might influence the consumption of industrial soft drinks in a context where there are several religious practices. Moreover, the fully adopted theories are the theory of sustainable development, the individualistic theory of consumer behavior, the collectivist theory of consumer behavior, the economic theory of consumer behavior and the culturalist theory of consumer behavior. These are deemed appropriate because they emphasize the role of the consumer and the importance of certain variables such as religiosity and consumer behavior. These theories are also adopted because they provide a clear explanation of culturalist behavior, individualistic behavior, and collectivist behavior of consumers in an environment where religiosity, an important aspect of culture, can exert influence on consumer behavior towards industrial nonalcoholic drinks.

In this literature review, the authors demonstrate that religiosity (Agarwala, Mishra \& Singh, 2018; Delener, 1989; Essoo \& Dibb, 2004) influence the behavior of consumers and that the solution to avoid boycotts of products, possible conflicts related to consumption and better understanding consumer deviant behavior in the form of dishonesty and immorality (e.g., shoplifting or fraud) is to conform to the religious and cultural values of consumers. The proposed solution takes into account the religious and cultural values of consumers but calls for involvement of companies, political authorities and are leading religious actors.

\section{Research propositions}

P1: Religiosity influences consumer behavior.

P2: Consumer behavior influences religiosity. 


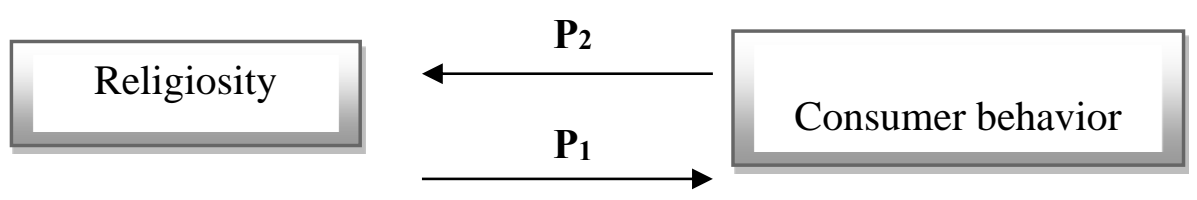

Figure 1: Research Model

(Source, adapted from Nasse et al. 2019)

\section{METHODOLOGY}

There is no prior marketing research in the context of Ghana and on the theme of culture and consumption. Therefore, this study is an exploration in the context of Ghana. The adopted epistemological stance is constructivist. The approach is inductive based on an exploratory qualitative approach, a literature review and observations. Conducting a qualitative study based on qualitative interviewing is of great significance for research like this. Van Campenhoudt and Charlier (2014, p. 120) shows the relevance of qualitative interview approaches through these words:

\section{" The major interest of a qualitative interview is that it not only brings factual information, but above all it allows to grasp the representations of the people interviewed, their worldview, that is to say how they perceive and appropriate their social environment and their own place and role in this environment."}

Research Instruments: This section focuses on the description of the interview guide used for qualitative data collection. It shows the number of questions contained in the interview guide, the development of the questions in the interview guide, or the origin of the questions in the interview guide. The search is conducted using a semi- structured interview guide. This semistructured interview guide is primarily addressed to consumers of non-alcoholic industrial beverages in the context of Ghana. The number of questions is fifteen (15). These interview guide questions are constructed using the different variables identified by the literature review.

Research Procedure: This section highlights the sampling strategy for locating the participants with whom semi-structured interviews are conducted, and the way qualitative data are recorded in the field of research.

First, the qualitative sampling strategy to locate participants to consist of identifying places (restaurants and snack bars or commonly called "drinking spots" in Ghana) where non-alcoholic industrial drinks are sold. Consumers of non-alcoholic industrial drinks are contacted and invited for an interview at their own free time. The semi-structured interview takes place either at the participant's home or at a suitable place chosen by the participant, a place where there is less noise as part of the ethical research considerations. Once the first participants have been identified, these participants are requested to invite other dedicated participants who meet the research criteria, and who are familiar with them and who also agree to participate regularly in the study. This qualitative study is done using a semi-structured interview guide, addressed to ten (10) respondents who are experienced consumers of industrial beverages. Recordings of interviews are made using a "voice recorder SONY", then these interviews are fully transcribed by hand; so the work from collection to transcription and processing is done entirely by the researchers, ensuring that the data is reliable. The "saturation criterion" is the criterion used to 
stop data collection, because the last interview usually does not give more information, as Van Campenhout and Charliet (2014, p. 94) point out:

Saturation is the second criterion proposed by Glaser and Strauss; it appears when the researcher finds that the latest information collected no longer provides significant added value compared to those collected previously. Any additional maintenance brings little new knowledge. Therefore, the researcher may decide to end the interviews.

Secondly, the sampling strategy used is the snowball approach based on referrals from earlier participants. The interview guide is first pre-tested with consumers of non-alcoholic industrial beverages. This first test is performed on a sample of ten (10) respondents. Pre-test results are used to write a final version of the interview guide. The designed interview guide is used again to conduct interviews with respondents. This second test is performed on a sample of ten (10) respondents. With such a sample, it is ensured that it meets the criteria of diversification and saturation (Van Campenhout \& Charliet, 2014, pp. 95-97); the criteria that make the results of this research very meaningful, and distinctive. From the ninth $\left(9^{\text {th }}\right)$ interview, there is already a saturation effect, however we decided to continue the recording of the semi-structured interviews until the tenth $\left(10^{\text {th }}\right)$ interview.

Qualitative Research Framework: This qualitative research is conducted in the city of Wa, northwestern Ghana. Not only is the choice of this city motivated on the grounds of proximity of the research field to the researchers, it is also motivated by the fact the city has a high concentration of religious people. It is as well a city with consumers of industrial beverages, restaurants and beverage outlets.

Research Participants: The participants are considered the following criteria, which include age, sex, religion, educational level, marital and occupation and social class status. First, the age of participants ranges from 10 to over 65 years old. Secondly, the gender of participants includes women and men who are animist, Christian or Muslim. Third, the level of education of participants ranges from primary school to university. Finally, the participants are also from different socio-professional categories of different social classes, and they must necessarily be consumers who have experience in the consumption of non-alcoholic industrial beverages.

Data Analysis: The analysis of qualitative data is summarized in the analysis of the data collected during interviews with the various respondents in this research. First, after handwriting the qualitative data using the audio software "SONY sound organizer", a content analysis is performed by considering the different topics and the most relevant verbatim. Secondly, the data from the qualitative study is also supplemented by direct observation and a literature review.

Validation of Research: According to Carricano (2010), the measurement instruments chosen must make it possible to better understand the phenomenon to be measured and to measure what we want to measure. For White (2002), for example, the validity of a research is that the research is fully consistent with the research questions and objectives (White, 2002, p. 26). First, the interview guide is validated as adapted from Nasse (2018). After the data collection and analysis, a post validation of the data is also done to ensure that respondents repeat the same points of view.

Internal Validity: To ensure the quality of the questions and answers, the quality of the number of collections, two methods are used to validate the information collection tools. A pre-test is 
conducted with 5 respondents to ensure that the various questions are well understood. To reduce the incidental sources of errors, the qualitative questionnaire of the interview guide is revised and then re-adapted following notified observations. In this process, it is necessary to ensure that the sample composition and the selection mode of the sample is good and representative and that the sample has no bias.

External Validity: To increase the precision of the results, the research carried out is reassuring as regards the representativity of the sample (sampling); the saturation and diversification of the sample (Van Campenhoudt \& Charliet, 2014) which makes the data more relevant. Responses from respondents who are consumers of non-alcoholic beverages in all the companies visited abound in the direction of the expected results, so this can be outsourced to other companies.

Reliability of Qualitative Research: According to Carrino et al. (2010, p. 61) there is a reliability of an instrument when this instrument constantly measures the construct to be measured. The 'test' and 'retest' method is one of the best reliable measurement procedures (Carrino \& al., 2010). The data are measured on a regular basis with the same instruments and the same results are obtained after testing and retesting the data on the same population.

\section{RESULTS}

For a qualitative approach semi- structured interview has been administered to a total of ten (10) individuals. They are animists, Christians and Muslims, including men numbering eight (8) and women numbering two (2). These respondents belong to different social classes and have a level of education from primary to university and living in the city of Wa in Ghana. Regarding religious affiliation we have seven (7) Christians, two (2) Muslims and one (1) animist (see Table 1 below).

Table1

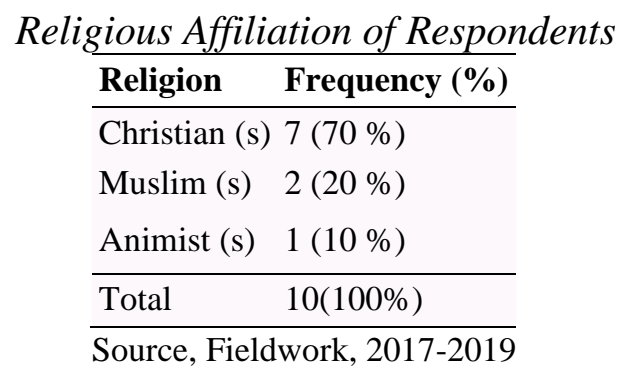

A further analysis of the results reveals clear viewpoints on the religiosity and consumer behavior nexus with respect to non-alcoholic industrial beverages in the context of Ghana as supported by fallouts from interviews with respondents vis a vis the propositions driving this study. Firstly, the results supports the view that, religiosity positively or strongly influences consumer behavior in the sector of non-alcoholic industrial beverages. This position is supported by interview extracts when it is noted that, Christians prefer non-alcoholic industrial beverages:

\section{"...I am presbyterian. For the Presbyterian, it is forbidden to drink industrial alcoholic drinks." (Respondent 7, 20 years old)}

I'm from a Christian denomination which is the Pentecost. My belief in my religion is that there are thirteen things one should go through. I 
stand in God in order to defend my religion. I am very strong and I will be able to help you in your religion. Well, I have been a preacher of the word of God. I do preach the word of God. As a Christian and as to my religious belief we should not give ourselves to industrial alcoholic drinks... so talking about industrial non-alcoholic drinks then my religion will just recommend that. " (Respondent 5, 25 years old)

The perspectives of the Muslims are not different from the Christians when it is also observed from the interviews that, Muslims also consume non-alcoholic industrial drinks (see extracts from respondents $1 \& 7$ ):

"I am an Ahmadiyya Muslim and according to my religious faith, no one is allowed to consume alcoholic industrial drinks. We are allowed to consume only non-alcoholic industrial drinks. " (Respondent 1, 45 years old)

" I am a Muslim. Yes, I am committed to my religious belief (...)

Islam says that alcoholic drinks are good for consumption. These ones we can drink them because they do not contain any alcohol. (...) I will consume the industrial non-alcoholic drinks, because my religious belief says that I should not take alcoholic drinks. (Respondent 7, 20 years old).

\section{Consumer Behavior Positively and Strongly Influences Religiosity.}

Some respondents point to the misbehavior associated with the consumption of industrial alcoholic beverages and therefore prefer non-alcoholic industrial drinks. This shows that consumer behavior affects religiosity, especially when the consumer behaves in a bad way. Extracts from respondent $3 \& 5$ posits that:

"Religiosity is what makes my life go a long way. I am a Pentecost and as Christ says that we should imitate him, I do not drink industrial alcoholic drinks, because I do not want to lose my mind and misbehave. I drink industrial non-alcoholic drinks like malta guinness "(Respondent 3, 17 years old).

"Consumption of industrial alcoholic drinks is something that is harmful to Christians. There is something attached to that. There is something very strange with a Christian being a drunkard as well. In my religious belief we will strongly go for industrial non-alcoholic drinks. "(Respondent 5, 25 years old)

A further interrogation of the most cited non-alcoholic industrial beverages in this research reveal that Malta guinness is in first position with a percentage of popularity of 23.52\%; then Coca-Cola is in second place with a percentage of popularity of $17.64 \%$; then Alvaro and Fanta in third position with each a percentage of popularity 
of $11.76 \%$; and finally come Pepsi, Royal apple, Sprite, Sobolo and Voltic, each with a popularity percentage of $7.06 \%$.

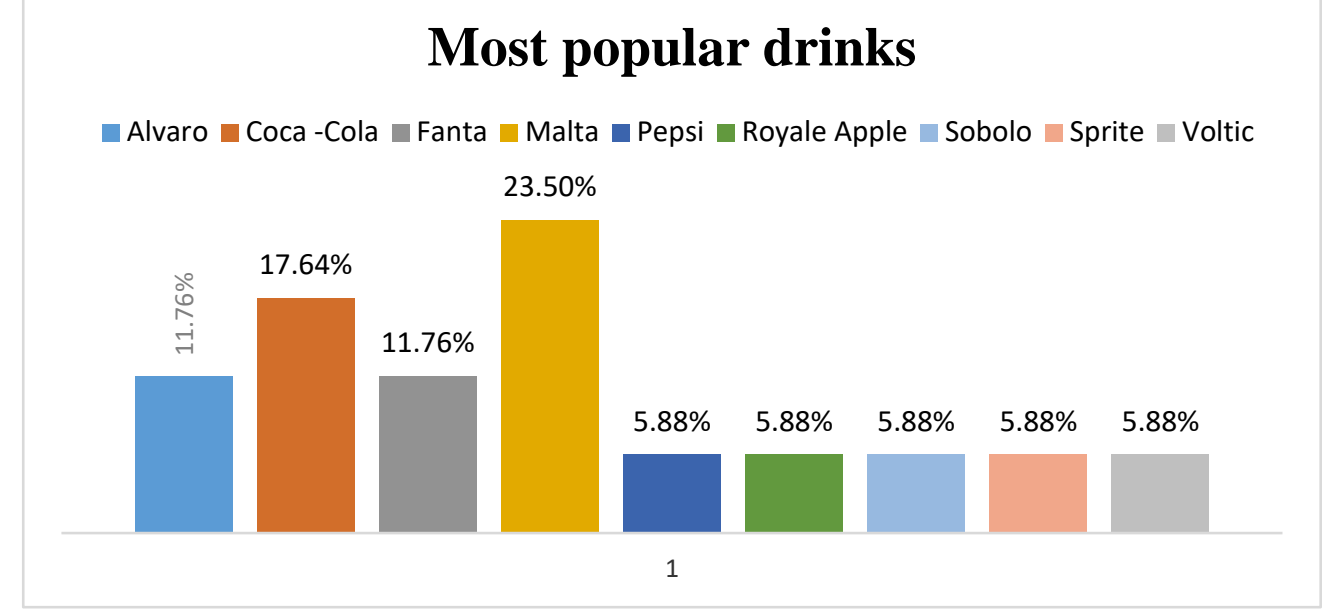

Figure 2: Most popular industrial soft drinks

Source: Fieldwork

\section{DISCUSSION}

An analysis of research field results clearly shows that there is a probable relationship between religiosity and consumer behavior with respect to non-alcoholic industrial beverages (Amankwaa \& al., 2012; Nasse, Ouédraogo \& Diop, 2019). The results clearly show that most respondents, be they animist, Christian or Muslim, say they consume non-alcoholic industrial drinks under the dictates of religious considerations including the fear of getting intoxicated from consuming alcoholic beverages and getting separated from the devine protection of God and losing heaven in the protection. This finding is in line with the view espoused by Mathras et al (2018) who noted that dimensions of religiousity including the beliefs, values and community belongingness tend to moderate consumption behaviors based on the religious beliefs about the afterlife and the fear of punishment for violating a religious values Proposition 1 can be confirmed. Thus, the first proposition $\left(\mathrm{P}_{1}\right)$ : Religiosity influences the behavior of consumers is confirmed

Second, the previous study conducted in the context of Burkina Faso, on religiosity and consumer behavior has succinctly demonstrated that consumer behavior seems to have an effect on religiosity (Nasse, Ouédraogo \& Diop, 2016, p. 16). In the context of Ghana the results and observations show that consumer behavior with respect to non-alcoholic beverages influences religiosity. An equally relevant finding is that consumer behavior in religious areas shows that believers consume only non- alcoholic industrial beverages which influences the religiosity of the individual. Proposition 2 can be confirmed. The finding which suggested that non-alcoholic beverages ensured conformity to guidelines and creed also confirmed the fact that, an individual's consumption pattern often tend to typify the extent to which they are religious. Thus, the second proposition $\left(\mathbf{P}_{2}\right)$ : Consumer behavior influences religiosity is verified.

\section{CONTRIBUTIONS TO RESEARCH}

Conceptual Contributions: The main conceptual contributions are based on the enrichment of concepts such as religiosity and consumer behavior. These concepts have already been defined by leading authors of English literature and French literature in the Western context, in the Asian context; and also in the African context. However, these concepts have been discussed, 
analyzed and re-enriched in the context of Ghana to redefine them because of specific needs related to their understanding and uses.

Methodological Contributions: In terms of contributions to methodological research, it is essential to recognize that the methodological approach in the context of Ghana takes into account socio-cultural realities such as the language and cultural barrier.

Managerial Contributions: Concerning the managerial contributions of research, it aims to identify concrete conflicts (intra-religious and inter-religious conflicts) related to the consumption of industrial drinks (Nasse, Ouédraogo \& Diop, 2016) and to see how these problems can be solved in the Ghanaian context. In this research it is clear that evangelical Christians and Muslims are more demanding because it is the religious groups who strongly claim the consumption of non-alcoholic industrial drinks while animists and Catholics are less demanding. Thus evangelical Christians and Muslims are not tolerant towards industrial alcoholic consumption while Animist and Catholics are more tolerant towards industrial alcohol consumption. Consumers appreciate some positive aspects of non-alcoholic industrial beverages. This is reflected in this respondent's point of view.

"Well if no one in my country consumes any industrial alcoholic drink and rather drink non-alcoholic drinks then there will probably be peace. The reason is that when everybody drinks alcoholic beverages; drivers who are also drunkards may be talking about influence of alcohol. In fact everybody will be in a normal circumstance, because they think, it's okay. So when a consumption of non-alcoholic drinks occurs then people will actually go to stay and do good things. "(Respondent 5, 25 years old)

"Firstly, we are not alcoholic drinks consumers, we the Muslims in term of consumption, because we do not take alcoholic drinks. Secondly, it is good for small children, because one cannot buy alcohol for small children." (Respondent 7, 20 years old).

However, some consumers do not like the contents of some non-alcoholic industrial beverages because they contain elements not recommended by religious faith :

"Some industrial non-alcoholic drinks give you some coffee taste and some contain coffee, and the other is good caffeine what is not good. As a muslim my expectations are that first industrial non-alcoholic drinks should not contain a substance like caffeine and alcoholic drinks not second industrial should contain excess of sugar; because the coffee and the excess of sugar can harm the body. "(Respondent 7, 20 years old).

"When we talk about three negative point we know that, we can talk about the drinks that contain too much gas. These types of nonalcoholic drink can be used in one's body, which is a result of too much gas, and then there are some other kind of sicknesses and then they are more likely to it can become a cost to sellers.

(Respondent 5, 25 years old). 


\title{
CONCLUSION AND IMPLICATIONS
}

To better meet consumer expectations in the context of Ghana, it is good for management to consider religiosity in the industrial beverage sector. Such involvement can make it easier to adapt industrial beverages to consumers' tastes and to meet their basic needs, and also a solution to eradicate poverty, social and religious conflicts, a factor of sustainable development and job creation (Nasse, Ouédraogo \& Diop, 2016; Dumbili, 2013). Unlike other contexts, in the Ghanaian context different religious beliefs (Traditionalists/Animists, Christians and Muslims) pray together publicly when the cause is common. However, evangelical Christians and Muslims are much more demanding in the consumption of non-alcoholic industrial beverages and prohibit the consumption of industrial alcoholic beverages. Catholic Christians and animists are less demanding in the consumption of non-alcoholic industrial drinks, but they advise moderation in the consumption of industrial alcoholic beverages in line with the values of frugality and thrift (Dana \& Dana, 2008; Guiso, Sapienza \& Zingales, 2003). In the case of the catholic Christians in particular, excessive intake of alcoholic beverages could attract sanctions including some temporary suspension of rights to Church leadership among others.

Recommendations for Companies in the Beverage Sector: It is very important to take into account the concept of religiosity in the manufacture, marketing of industrial beverages and in the management of companies in this sector of activity. This involves the diversification of the non-alcoholic industrial drinks sector with innovative, high-quality products that also take into account the expectations and needs of religious and non-religious, by involving them in the production and management process (Nasse, Ouédraogo \& Diop, 2016; Dumbili, 2013). We must seek to eliminate as much gas, excess sugar and substances such as caffeine in these drinks and make their content more appreciable to the taste and health of the consumer. The price of non-alcoholic industrial beverages should also be reviewed as some respondents find them too high:

\begin{abstract}
"The relevant ideas and suggestions I can add is that manufacturers of nonalcoholic industrial beverages should get up to at least add value, reduce prices and put good ingredients that will help them in the process. Manufacturing and in the sale and at least people will be able to have these drinks and stay away from alcoholic industrial drinks. If probably the government can get up and do something good by improving things I think it will be good "(Interviewed 5, 25 years)
\end{abstract}

Recommendations for the Ghanaian Authorities: The study shows that religiosity deeply influences consumer behavior with respect to non-alcoholic industrial beverages. Thus, some respondents expect that the authorities move in the direction of lower prices for non-alcoholic beverage industry. Price reduction contributes to Ghana's poverty alleviation policy and strategy, as it will enable the very poor population to obtain these drinks and improve their living and health conditions, because industrial drinks are food complements (Sow, 2005; Nasse, 2018) and also they have a medical function (Nasse, Ouédraogo \& Diop, 2019). Other consumers are waiting to see the reduction of substances that harm people's health, such as excess gas and the presence of caffeine in some non-alcoholic industrial beverages. Not only are these drinks consumed by children and the presence of these various harmful substances 
can harm their health; but also these drinks are consumed by religious people who find that these substances do not suit to the prescriptions of their religious beliefs and their health. It appears from the study that some consumers admit that they consume both industrial nonalcoholic drinks and industrial alcoholic drink and the governmental authorities must also draw the awareness of manufacturing companies to raise consumer consciousness in relation to alcohol abuse which is however dangerous for the health. Authorities may also use the breathalyzer for lane checks to prevent drunkenness accidents (Nasse, 2018).

Future Research: It would be wise to extend this research to other African contexts or to investigate whether there is a relationship between consumption of alcoholic beverages and conflicts.

\section{Acknowledgments}

There researchers want to acknowledge the contribution of the respondents from the different religious affiliation (Christians, Muslims and Traditionalists).

\section{Conflicts of Interests}

The authors have not declared any conflict of interests.

\section{Funding}

This research has been made possible thanks to the support of German DAAD Program, and the University for Development Studies.

\section{References}

Addo J., Cook, S., Galbete, C., Agyemang, C., Klipstein-Grobusch, K., Nicolaou, M., et al. (2018). Differences in alcohol consumption and drinking patterns in Ghanaians in Europe and Africa: The RODAM Study. PLoS ONE, 13(11), e0206286. https://doi.org/10.1371/journal.pone.0206286

Agarwala, R., Mishra, P., \& Singh, R. (2017). Religiosity and consumer behavior: a summarizing review. Journal of Management, Spirituality \& Religion, 16(1), 32-34.

Ahmad, A. N., Rahman, A. A., \& Abd Rahman, S. (2015). Assessing knowledge and religiosity on consumer behavior towards halal food and cosmetic products. International Journal of Social Science and Humanity, 5(1), 10-14.

Alam, S.S., Mohd, R., \& Hisham, B. (2011). Is religiosity an important determinant on Muslim consumer behaviour in Malaysia? Journal of Islamic Marketing, 2(1), 83-96.

Al-Hyari, K., Alnsour, M., Al-Weshah, G., \& Haffar, M. (2012). Religious beliefs and consumer behaviour: from loyalty to boycotts. Journal of Islamic Marketing, 3(2), 155 174.

Amankwaa, A. A., Reed, W., \& Owens, De' A. (2012). Church attendance and alcohol consumption level: reasons for not drinking alcohol among college students. International Journal of Humanities and Social Science, 2(4), 1-8.

Bazié, J. (2011). Comprendre la communication en milieu traditionnel. Ouagadougou, OU : Les presses africaines. 
Baazeem, T. A. (2015). How religiosity influences consumption: the impact of consumer religiosity on perceptions of psychological and social risk. Brisbane, BR: QUT Business School.

Benabdallah, M., \& Jolibert, A. (2013). L'acculturation: l'influence des sous-cultures d'origine et de la distance culturelle. IDRAC business school, INSEEC business school et CERAG, UMR CNRS 5820. Décisions Marketing, 1(72), 179-205.

Bonewell, K. J. (2008). Intrinsic and extrinsic religiosity and sexual compulsivity with Christian males: understanding concepts and correlations based on race, age and socioeconomic status and marital status. Capella University 225 South Sixth Street Ninth Floor, Minneapolis, 6-30.

Campanella, M. R. (2016). Halal food consumption, responsibility, moral overtones and renegotiation of categories among Muslim believers in Stockholm County. Uppsala, UP: University of Uppsala.

Dana, L. P., \& Dana, T. E. (2008). Collective entrepreneurship in a Mennonite community in Paraguay. Latin American Business Review, 8(4), 82-96.

De Mooij, M., \& Hofstede, G. (2011). Cross-cultural consumer behavior: a review of research findings. Journal of International Consumer Marketing, 23(1), 181-192.

De Mooij, M. (2003). Convergence and divergence in consumer behaviour: implications for global advertising. International Journal of Advertising, 22(1), 183-202.

Delener, N. (1990a). The effects of religious factors on perceived risk in durable goods purchase decisions. Journal of Consumer Marketing 7(3), 27-38.

Diop, F. (2012). L'influence de la religion musulmane sur le comportement de consommation au Sénégal. École Supérieure Polytechnique de Dakar, Université Cheikh Anta Diop, Sénégal.

Diop, F. (2004). L'achat familial en Afrique. École Supérieure Polytechnique de Dakar, Université Cheikh Anta Diop, Sénégal.

Dumbili, E. (2013). Changing patterns of alcohol consumption in Nigeria: an exploration of responsible factors and consequences. A Journal of the BSA MedSoc Group, 7(1), 2033.

Essoo, N., \& Dibb, S. (2004). Religious influences on shopping behaviour: an exploratory study. Journal of Marketing Management, 20 (7/8), 683-712.

Esteban, J., Levy, G., Mayoral, L. (2015). Liberty, religiosity, and effort. Barcelona Graduate School of Economics Working Paper Series, 843(1),1-39.

Fam, K. S., Waller D. S., \& Erdogan, B. Z. (2002). The influence of religion on attitudes towards the advertising of controversial products. European Journal of Marketing, 38(5/6), 537-555.

Ghana Statistical Service (2012). 2010 Ghana Population and Housing Census. Accra, AC : Summary report of final resuts. p.84. (accessed 14.03.2015) http://www.statsghana.gov.gh/docfiles/2010phc/Census2010_Summary_report_of_fin al_results.pdf

Guiso, L. \& Sapienza, P. \& Zingales, L. (2003). People's opium? Religion and economic attitudes. Journal of Monetary Economics, Elsevier, 50(1), 225-282.

Howell, A. M. (1996). The religious itinerary of a Ghanaian people: the Kassena and the Christian gospel. New York, NY: Africa Christian Press. 
Ishak, S., Che Omar, A.R., Khalid, K., Ab. Ghafar, I.S., \& Hussain, M.Y. (2019). Cosmetics purchase behavior of educated millennial Muslim females. Journal of Islamic Marketing, https://doi.org/10.1108/JIMA-01-2019-0014.

Islam, T, \& Chandrasekaran, U. (2020). Religiosity and consumer decision making styles of young Indian Muslim consumers. Journal of Global Scholars of Marketing Science, 30(2), 147-169.

Jung, K. A, \& Kau, A. K. (2004). Culture's influence on consumer behaviors: differences among ethnic groups in a multiracial Asian country. Advances in Consumer Research, $31(1), 366-372$.

Kitchathorn, P. (2009). Factor influencing customer repurchase intention: an investigation of switching barriers that influence the relationship between satisfaction and repurchase intention in the low cost airlines industry in Thailand. University of South Australia.

Nassè, T. B. (2020). Religious beliefs, consumption and inter-religious differences and similarities: is syncretism in consumption a new religious dynamics? International Journal of Management \& Entrepreneurship Research, 2(2), 59-73.

Nasse, T. B., Ouédraogo, A., \& Sall, F. D. (2019). Religiosity and consumer behavior in developing countries: An exploratory study on Muslims in the context of Burkina Faso. African Journal of Business Management, 13(4), 116-127.

Nassè, T. B. (2018). Pratiques religieuses et comportement de consommation dans un contexte africain : une étude exploratoire sur les consommateurs au Burkina Faso. Ouagadougou, OU: Université Aube Nouvelle.

Nassè, T. B. (2015). Internal Equity as a Factor of Companies' Economic Profitability: A comparative study of three private companies in Burkina Faso through a qualitative approach. Saarbrücken, SA: Lambert academic publishing.

Nassè, T. B. (2012). Succeeding in Church missionarial work in West Africa: the necessity of understanding the West African environment. Saarbrücken, SA: Lambert academic publishing.

Nassè, T. B. (2006). Kasim borrowings from English: an evidence from Burkina Faso. Ouagadougou, $O U$ : A master thesis, University of Ouagadougou, Burkina Faso.

Nayeem, T. (2012). Cultural influences on consumer behavior. International Journal of Business and Management, 7(21), 79-91.

Nurbasari, A. (2015). The impact of spiritual marketing on consumer behavior in choosing halal food: case study on Muslim community in Bandung. Al Hijaz International Refereed Journal for Islamic and Arabic Studies, 273(10), 271-306.

Ouédraogo, A. (2007). Strategic management in African firms: a local perspective. Problems and Perspectives in Management, 5(1), 82-94.

Patel, M. (2010). Influence of religion on shopping behaviour of consumers: an exploratory study. National Monthly Refereed Journal of Research in Commerce and Management, $1(5), 68-78$.

Perconte, B. (2003). 50 Fiches pour comprendre le marketing. Paris, PA : Bréal.

Porter, C. (2013). The religion of consumption and Christian neighbor love. Loyola University Chicago.

Quéchon, M. (1971). Réflexions sur certains aspects du syncrétisme dans l'islam ouest-africain. Cahiers d'Études Africaines, 11(42), 206-230. 
Quivy, R., \& Van Campenhoudt, L. (2011). Manuel de recherche en sciences sociales. $2^{\text {ème } e ́ d . ~}$ Paris, Dunod.

Shamba, P. B., \& Livian, Y. F. (2014). Le management africain introuvable : pour une approche de l'hybridité segmentée. Marseille, MA: Communication pour la 4ème conférence Atlas-AFMI.

Simon, P. (2000). Pour une clarification de la relation entre attitude envers la marque et fidélité à la marque vers la mise en évidence d'un modèle intégrateur. Venezia, VE: Università ca' Foscari.

Sow, D. M. (2005). Alimentation et boissons au Burkina Faso: au-delà de la survie. Genève, GE: Bureau International du Travail.

Van Den Bergh, J. C., \& Nijkamp, P. (1991). Operationalizing sustainable development: dynamic economic models. Ecological Economics, 4(1), 11-34.

Van Laethem, N., \& Body, L. (2008). Le plan marketing. $2^{\text {ème } e ́ d . ~ P a r i s, ~ P A: ~ D u n o d . ~}$

\section{Websites visited}

1- https://en.wikipedia.org/wiki/Religion_in_Ghana October - 2017.

2- u-auben.com/articles-publies/ visited in September 2017.

\section{APPENDIX}

Table 2

\begin{tabular}{|c|c|c|}
\hline$\underline{\text { Age }}$ & Total number of respondents & Percentage \\
\hline $10-25$ years & 6 & $60 \%$ \\
\hline 26 - 35 years & 2 & $20 \%$ \\
\hline $36-45$ years & 1 & $10 \%$ \\
\hline 46 -and more & 1 & $10 \%$ \\
\hline
\end{tabular}

Table 3

Occupation of Respondents

\begin{tabular}{lll}
\hline Profession & Total number of respondents & Percentage \\
\hline Employees & 4 & $30 \%$ \\
\hline Unemployed & 6 & $10 \%$ \\
\hline \multicolumn{3}{c}{ Source: Fieldwork, 2017-2019 }
\end{tabular}

Table 4

Social Class of Respondents

Social class Total number of respondents Percentage

\begin{tabular}{llll}
\hline Very poor & 1 & $10 \%$ \\
\hline Poor & 3 & $30 \%$ \\
\hline Rich & 4 & $40 \%$ \\
\hline Very rich & 2 & $20 \%$ \\
\hline & Source: Fieldwork, 2017-2019
\end{tabular}

Table 5

Gender of Respondents

\begin{tabular}{lll}
\hline Gender of respondents & Total number of respondents & Percentage \\
\hline Male & 8 & $80 \%$ \\
\hline Female & 2 & $20 \%$ \\
\hline & Source: Fieldwork, 2017-2019
\end{tabular}


Table 6

Marital Status of Respondents

\begin{tabular}{|c|c|c|}
\hline Marital status & Total number of respondents & Percentage \\
\hline Single & 8 & $80 \%$ \\
\hline Maried & 2 & $20 \%$ \\
\hline Divorced & 0 & $0 \%$ \\
\hline
\end{tabular}

Table 7

Respondents' Level of Education

\begin{tabular}{|c|c|c|}
\hline Level of education & Total number of respondents & Percentage \\
\hline Illiterate & 0 & $0 \%$ \\
\hline Primary & 1 & $10 \%$ \\
\hline Secondary & 3 & $30 \%$ \\
\hline University & 6 & $60 \%$ \\
\hline
\end{tabular}

Source: Fieldwork, 2017-2019 